\title{
Fault Ride-Through Study and Control of a Wind Turbine Driving Squirrel Cage or Doubly-Fed Induction Generator: A Comparative Study
}

\author{
Mahmoud Essam M. Harby*, Helmy Elzoghby, Aboubakr Salem, S.E. Elmasry, Adel El Samahy \\ Department of Electrical Power and Machines \\ Faculty of Engineering \\ Helwan University (Cairo, Egypt) \\ ${ }^{*}$ Corresponding author's email: eng.mahmoudessam [AT] yahoo.com
}

\begin{abstract}
The renewable energy systems are going to take over most of the non-renewable energy systems, so many scientific efforts are being made to ensure the stability and reliability of the renewable energy systems. This paper is concerned about the wind energy systems and ensuring their behavior and performance during and after the abnormalities like fault ride-through. Two complete models of a grid connected wind systems are going to be simulated in the MATLAB software program, the first one will be a grid connected wind turbine driving a threephase squirrel-cage induction generator (SCIG) and the other model will be a grid connected wind turbine driving a three-phase doubly-fed induction generator (DFIG). The frequency of each system will be displayed and compared to the frequency of the other system upon fault ride-through (three-phase short-circuit fault) and under the effect of the PID controller which is tuned by genetic algorithm technique. The different responses of both generators are going to be analyzed graphically and compared to each other upon the ride-through fault and under the effect of the designed controller (genetic algorithm PID controller).
\end{abstract}

Keywords- Fault ride-through, Three-phase squirrel-cage induction generator, Pitch angle controller, Three-phase doubly-fed induction generator, Genetic algorithm PID controller.

\section{INTRODUCTION}

In the recent ten years the world energy generation from the wind system has been growing rapidly, this is due to the many benefits of the wind energy. Lots of scientific work has been done with such energy resource which encouraged the stakeholders to develop the wind systems and invest much money on such fields. According to the global wind energy council (GWEC) the global installed wind power capacity until 2016 was 3,906 MW in Africa \& Middle East, 203,685 MW in Asia, 153,729 MW in Europe, 15,296 MW in Latin America \& Caribbean, 88,283 MW in North America, 4,823 MW in Pacific Region (Australia, New Zealand and Pacific Islands) [1]. The statistics give an indication about the massive penetration of the wind energy systems into the world energy generation, according to the global wind energy council GWEC the global annual installed wind capacity in 2014 was 51,675 MW, in 2015 was 63,633 MW and in 2016 was 54,600 MW. From another aspect, the world wind energy leading countries in 2016 were China and USA, where the added installed wind energy capacity during 2016 in China was 23,328 MW, in the USA was 8,203 MW, and in Germany was 5,443 MW only in 2016. In this paper a full simulation of a wind system connected to the grid is going to be provided, and a fault ride-through is going to be applied to the transmission lines between the system and the utility grid, which has effects on the frequency of the wind system output power, so a pitch angle controller will be designed to adjust the pitch angle of the wind turbine blades [2]. This case study is going to be applied on two different systems the first one will be a grid connected wind turbine driving SCIG and the second case study will be a grid connected wind turbine driving a three-phase doubly-fed IG. The results of both cases are going to be compared together to ensure which one is more stable and robust against disturbances and transitional actions that may happen to the system [3].

\section{WIND SYSTEM GENERATORS}

There are three basic types of generators can be used with the wind systems, these generators are the three-phase squirrel-cage IG, the three-phase doubly-fed IG, and three-phase synchronous generator. This research is focusing on the state of the art type of generators, which is the three phase doubly-fed induction generator (DFIG), which can operate at speeds slightly above or below the synchronous speed, this advantage is very important for the large variable speed wind turbines, because the wind speed isn't constant and may change anytime, So in case of using the synchronous type, which is locked to the speed of the grid it connected to and the speed of the wind got changed, so the synchronous generator can't cope up with the change that happened on the wind speed because it's locked to the grid speed, this leads to a large force on the hub or the gearbox. The main advantage of the three-phase doubly-fed IG used with the wind 
systems that it can cope up with the change of the wind speed and maximize the output power, this is due to its innovative construction and principle of operation. Fig. 1 shows a general layout of wind turbine driving a three-phase doubly-fed induction generator DFIG and connected to the utility grid [6].

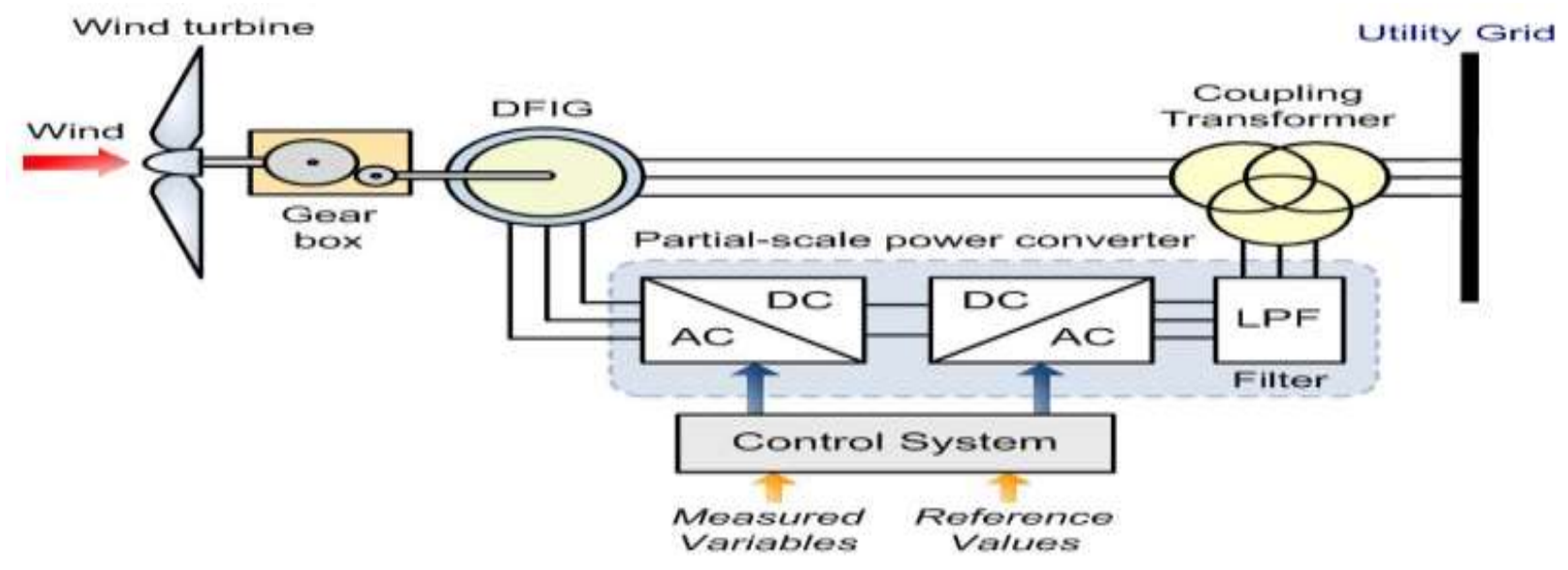

Figure 1: General Layout of a Wind System with DFIG.

\section{SYSTEM MODELLING}

The wind turbine model is created by the MATLAB software program. Fig. 2 illustrates the model of the proposed turbine. Table 1 depicts the wind turbine parameters. Fig. 3 presents the first case study system simulation. Fig. 4 shows the second case study system simulation created by MATLAB software program [6].

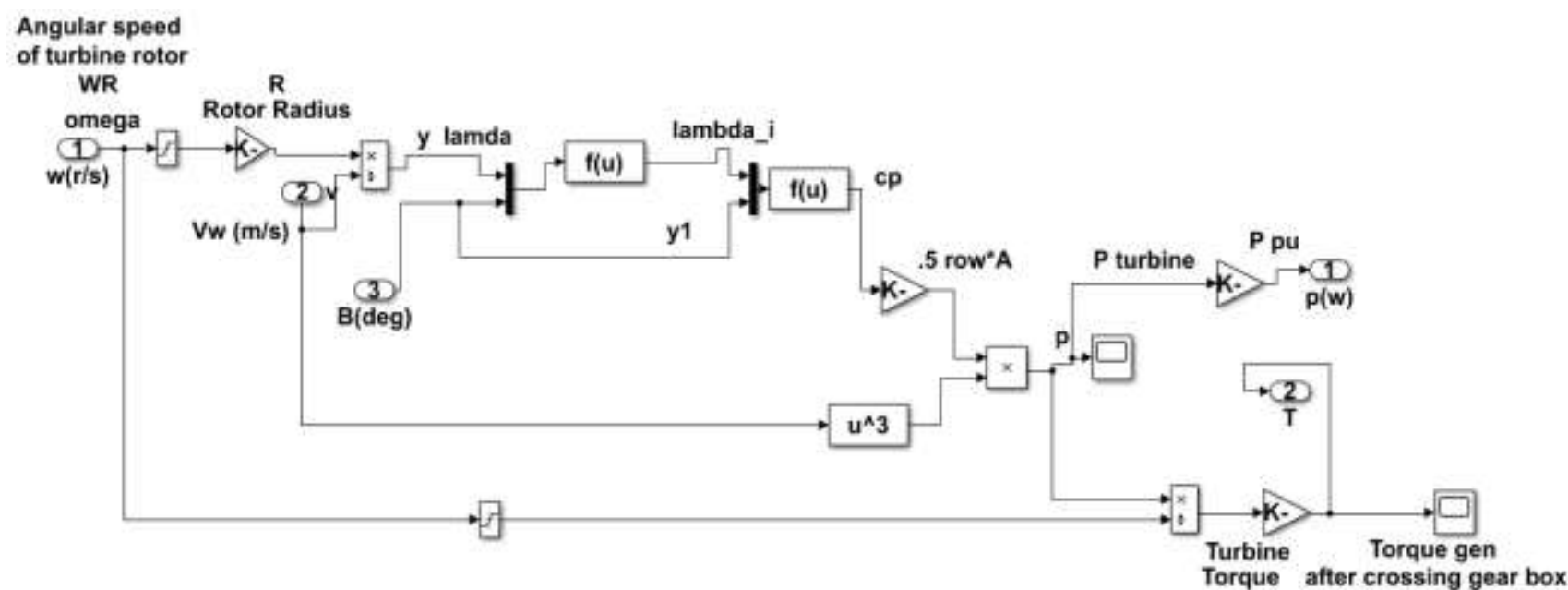

Figure 2: Wind Turbine Model. 
Table 1: Shows the parameters of the proposed turbine.

\begin{tabular}{|c|c|}
\hline The rotor mechanical power [MW] & 0.5 \\
\hline The rotor blade radius [m] & 17 \\
\hline The rotor angular speed [ $\mathbf{r a d} / \mathbf{s e c}]$ & 4.5 \\
\hline The air density [ $\mathbf{k g} / \mathbf{m} 3]$ & 1.225 \\
\hline Gear box ratio & 37 \\
\hline The rated wind speed [m/sec] & 13 \\
\hline Cut-off wind speed $[\mathbf{m} / \mathbf{s e c}]$ & 15 \\
\hline Number of rotor blades & 3 \\
\hline
\end{tabular}

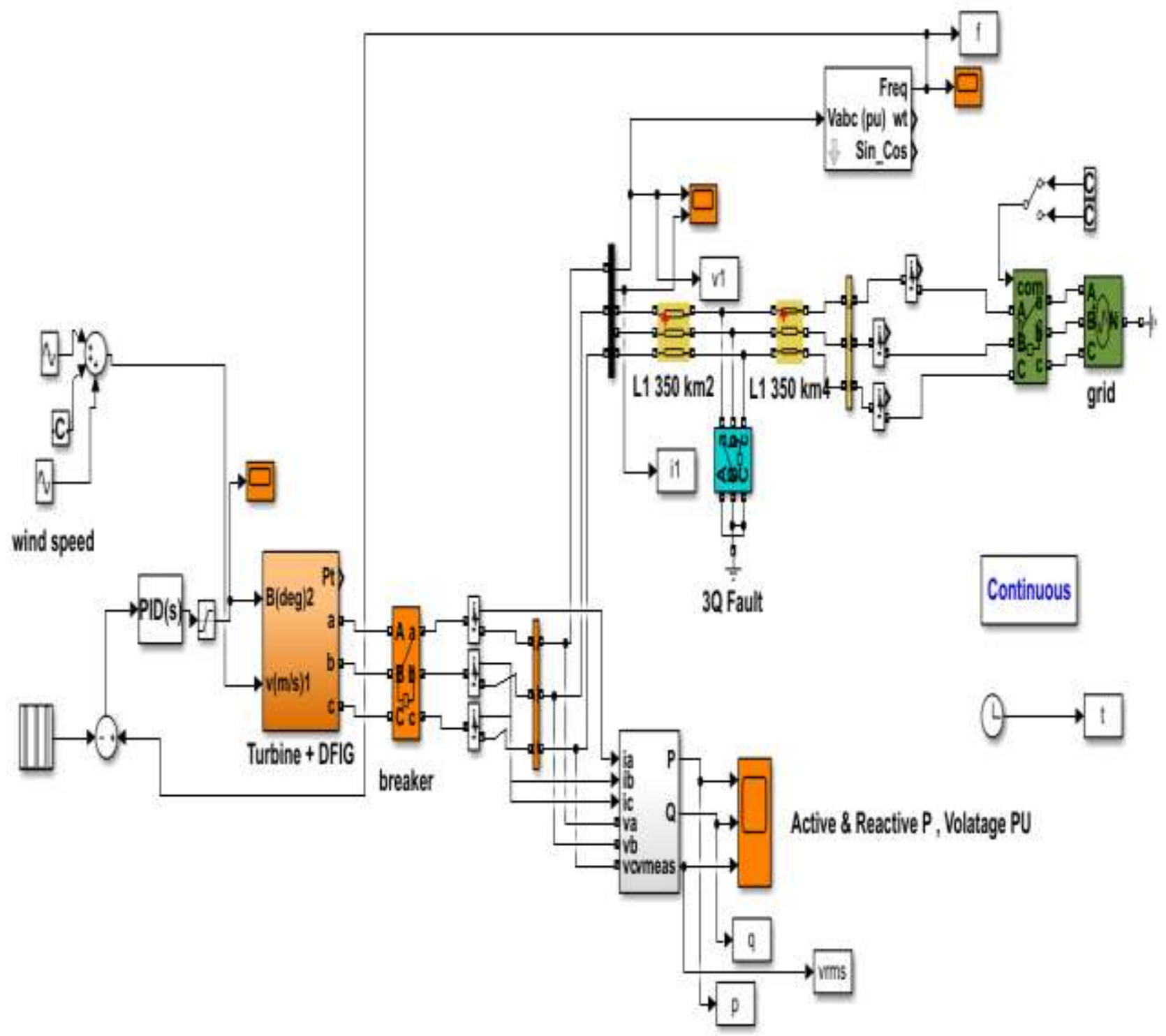

Figure 3: Wind System Driving DFIG. 


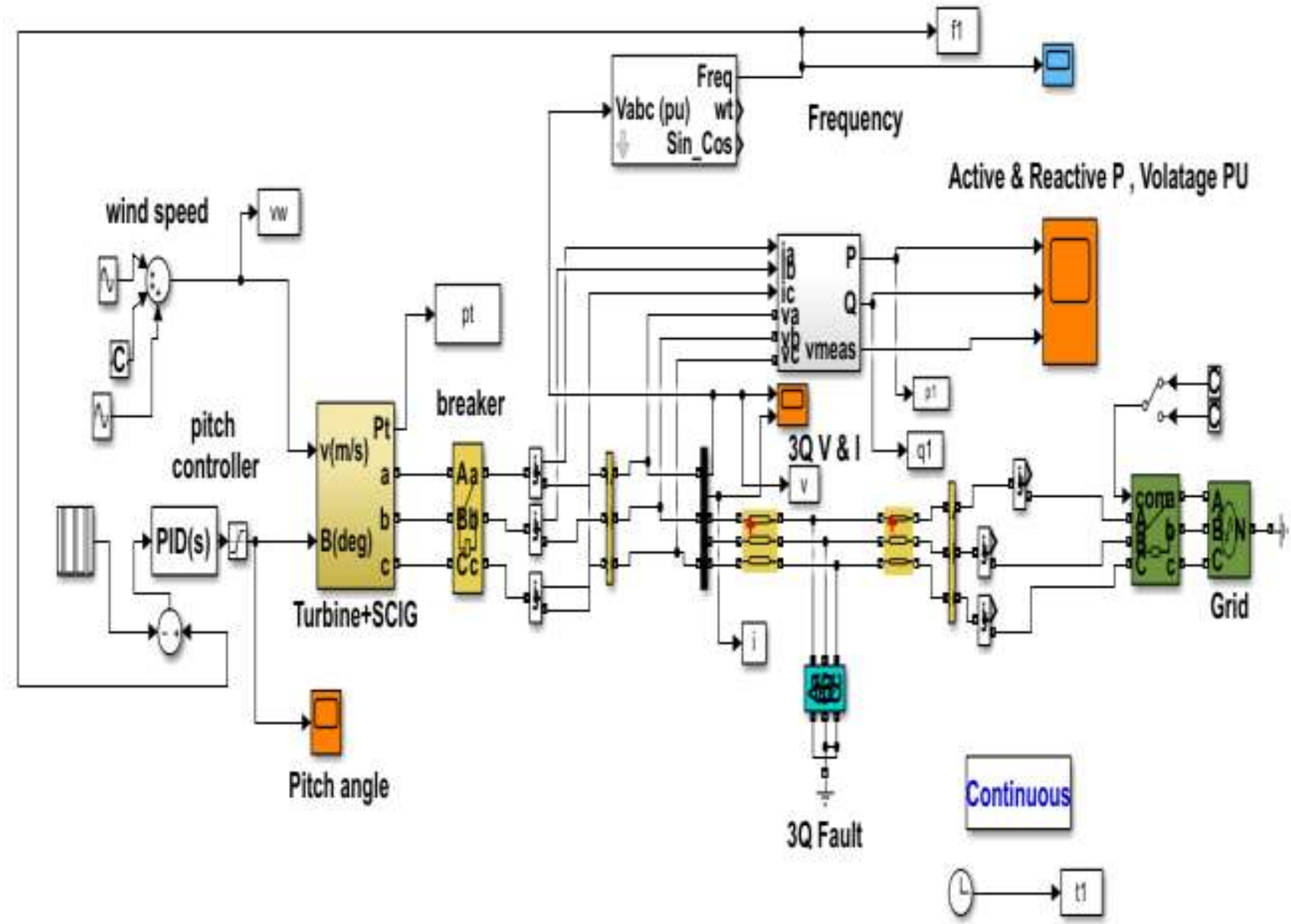

Figure 4: Wind System Driving SCIG.

\section{THREE-PHASE SHORT-CIRCUIT (SC) FAULT}

The model consists of the wind turbine, the gearbox, the induction generator, the suitable step up transformer, the transmission line T.L and the utility grid. The target of this paper is to apply a severe fault on the wind systems as described in Fig. 5 and Fig. 6. The fault is applied on the two case studies to check which type of generators is more stable and robust against the disturbances, the severe faults like the three-phase short-circuit fault and the transitional actions that may happen to the system [8].

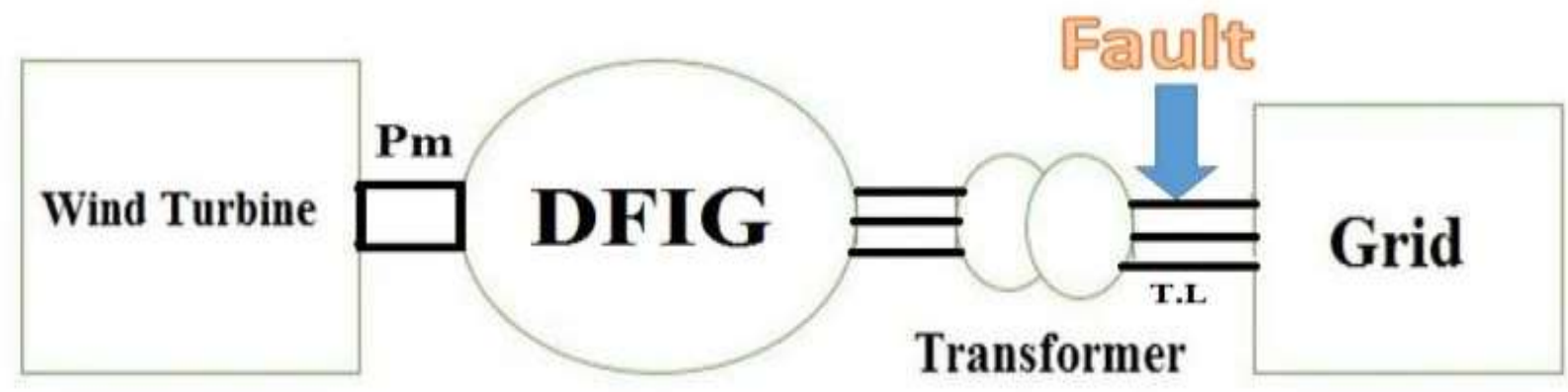

Figure 5: General Layout of the Proposed System with DFIG. 


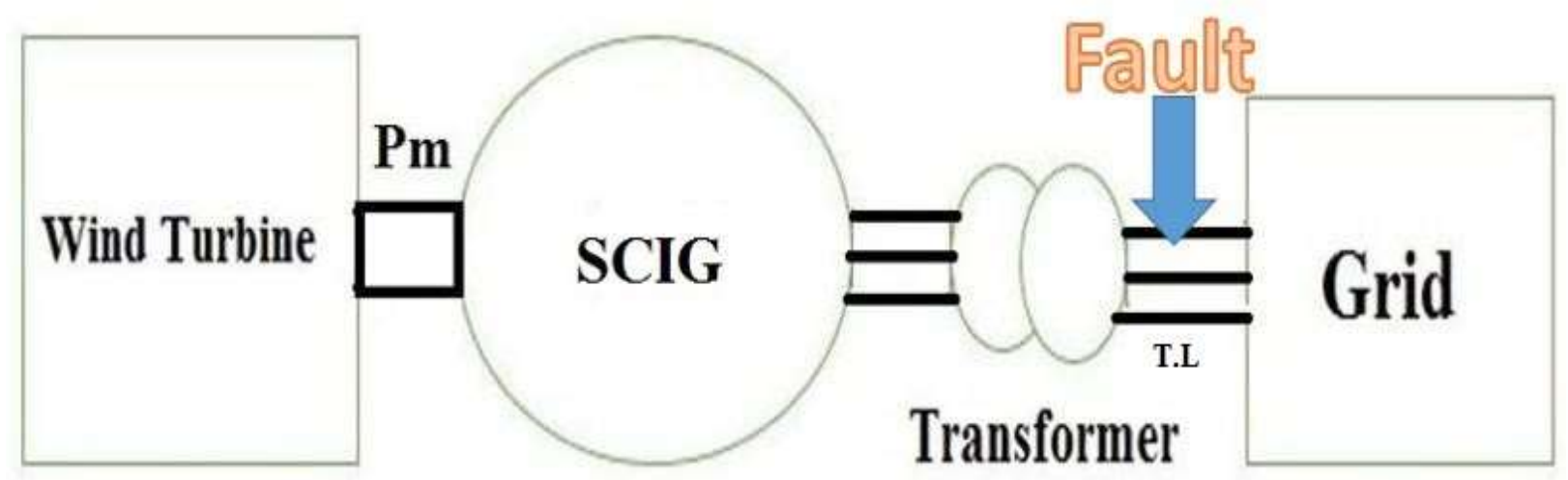

Figure 6: General Layout of the Proposed System with SCIG.

\section{GENETIC ALGORITHM OPTIMIZATION TECHNIQUE}

The basic principles of GA were first proposed by Netherlands, this technique was inspired by the mechanism of natural selection, a biological process in which stronger individual is likely to be the winners in a competing environment. GA uses a direct analogy of such natural evolution to do global optimization to solve highly complex problems (Mahony \& Downing, 2000). The genetic algorithm optimization technique can be used in control systems to get the optimal gains of the PID controller and its derivatives. This technique saves a lot of time, effort, and very accurate. Fig. 7 illustrates the genetic algorithm steps in a simple flowchart [5]. This controller is designed to adjust and control the pitch angle of the turbine blades during the wind variations and other abnormal cases like three-phase short-circuit fault. The designed controller mitigates the oscillation of the system frequency during severe faults that applied in this research.

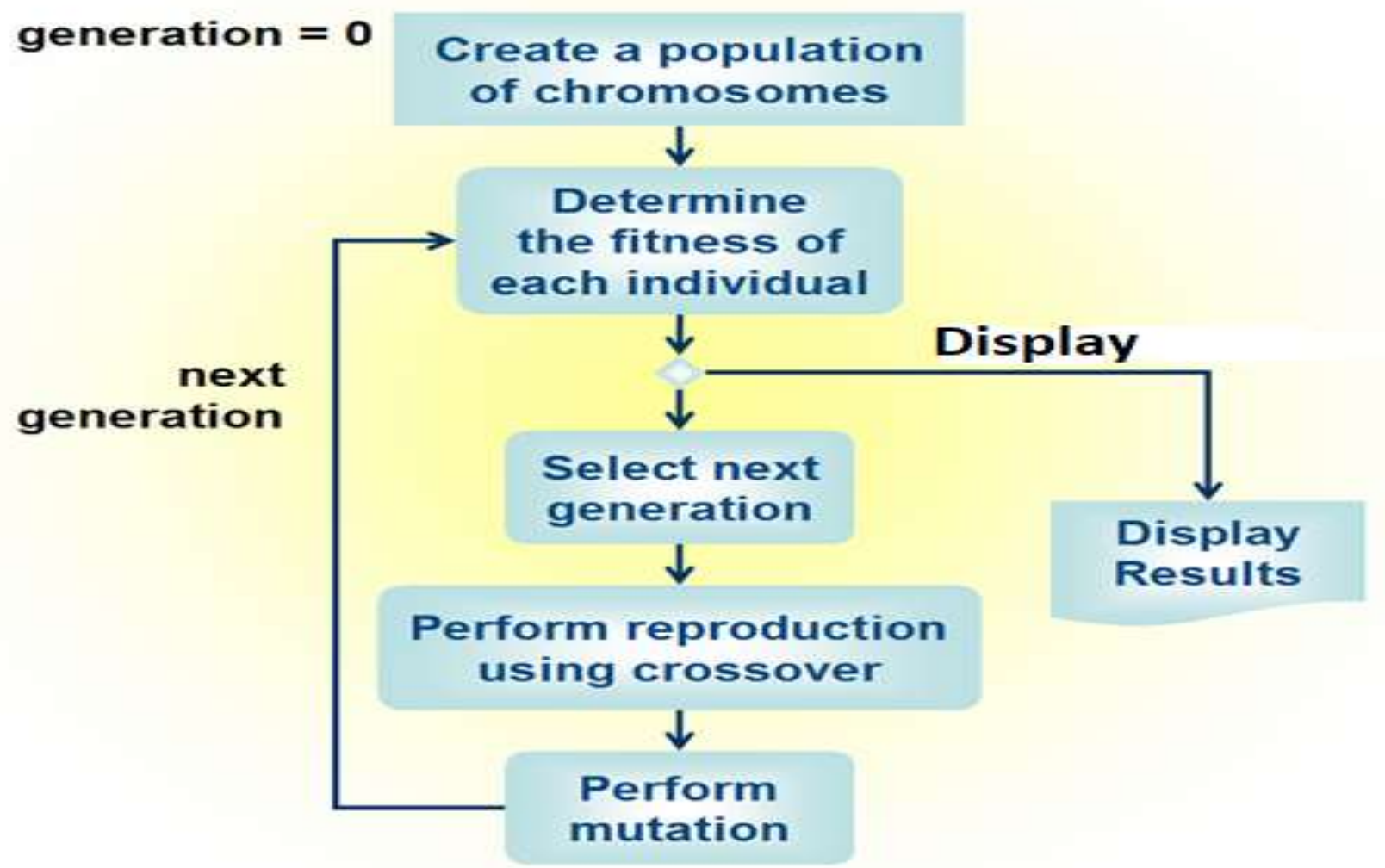

Figure 7: Steps of the Proposed Optimization Technique. 


\section{RESULTS}

In this section the results of each case are shown with a fruitful comparison with the other case. Fig. 8 shows the effect of the three-phase short-circuit fault on the wind system output power frequency for the two case studies (SCIG \& DFIG) and how the designed controller (PID tuned by Genetic Algorithm) was effective to a big extent and it has controlled the frequency response to be so close from the rated frequency during the fault occurrence as shown in the results. It can be noted that the response of the frequency in the DFIG case is better than the SCIG case for the same fault type, position and duration. Fig. 9 shows the effect of the severe fault on the DFIG \& SCIG active power.

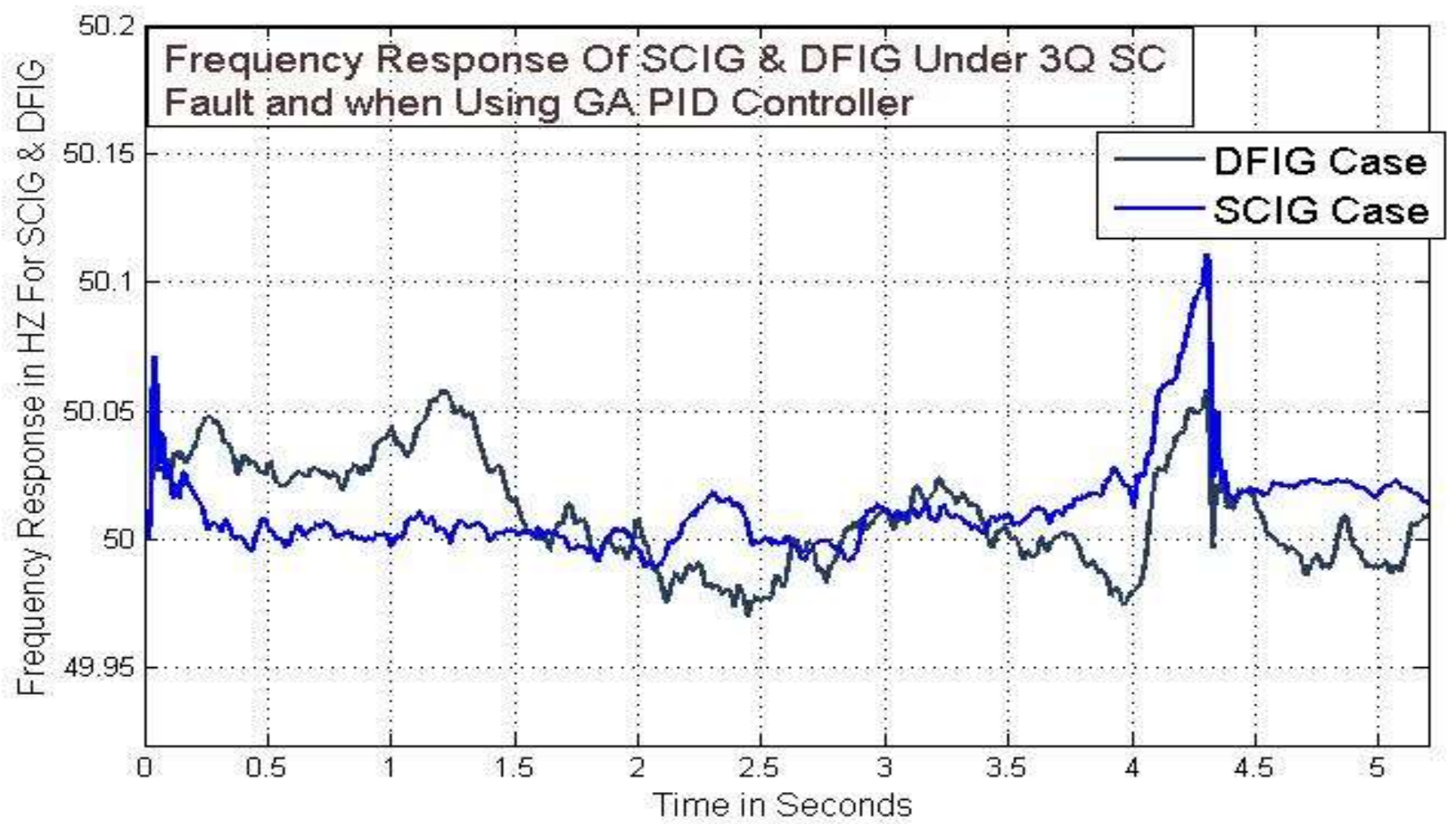

Figure 8: Frequency Response of Both Wind Systems.

Fig. 9 and Fig. 10 show the effect of the three-phase short-circuit fault on the DFIG \& SCIG output active and reactive power before, during and after the fault occurrence.

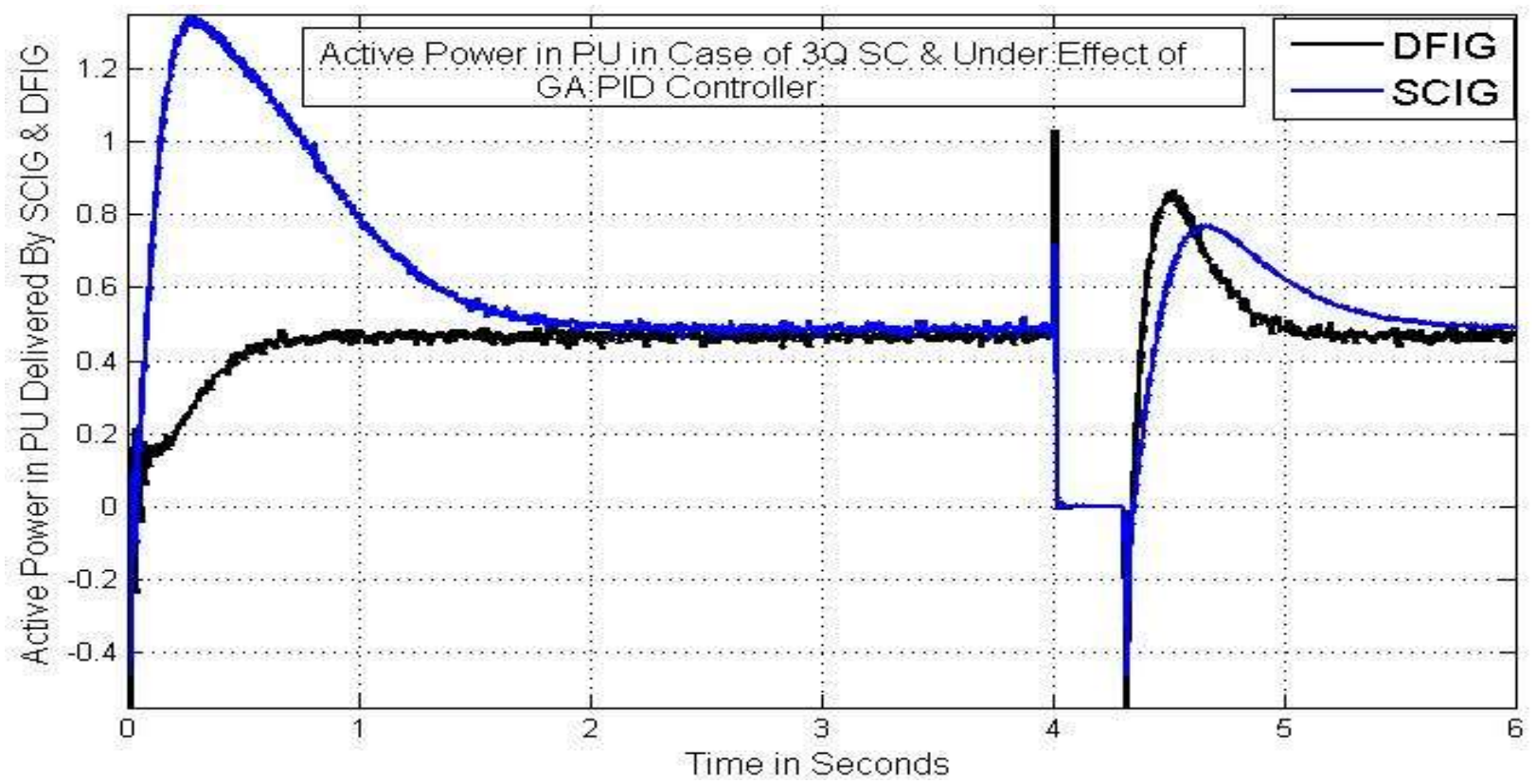

Figure 9: Active Power Response. 


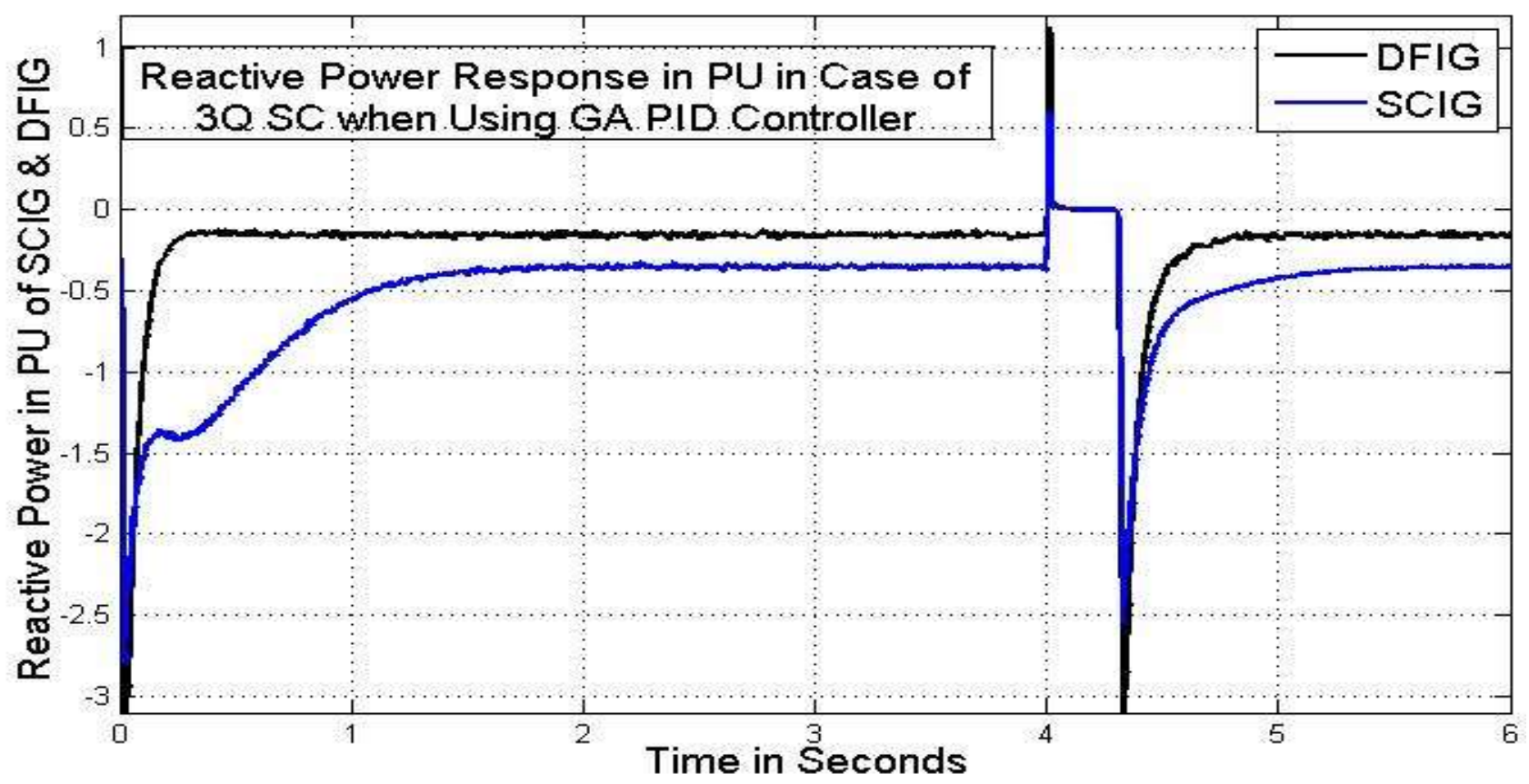

Figure 10: Reactive Power Response.

Fig. 11 shows the DFIG \& SCIG rotor speed before, during and after the fault occurrence and how the response of them was affected by the three-phase short-circuit fault causing the generator to be accelerated, but after the controller intervention the designed controller, the speed returned to the nominal value in a very fast way.

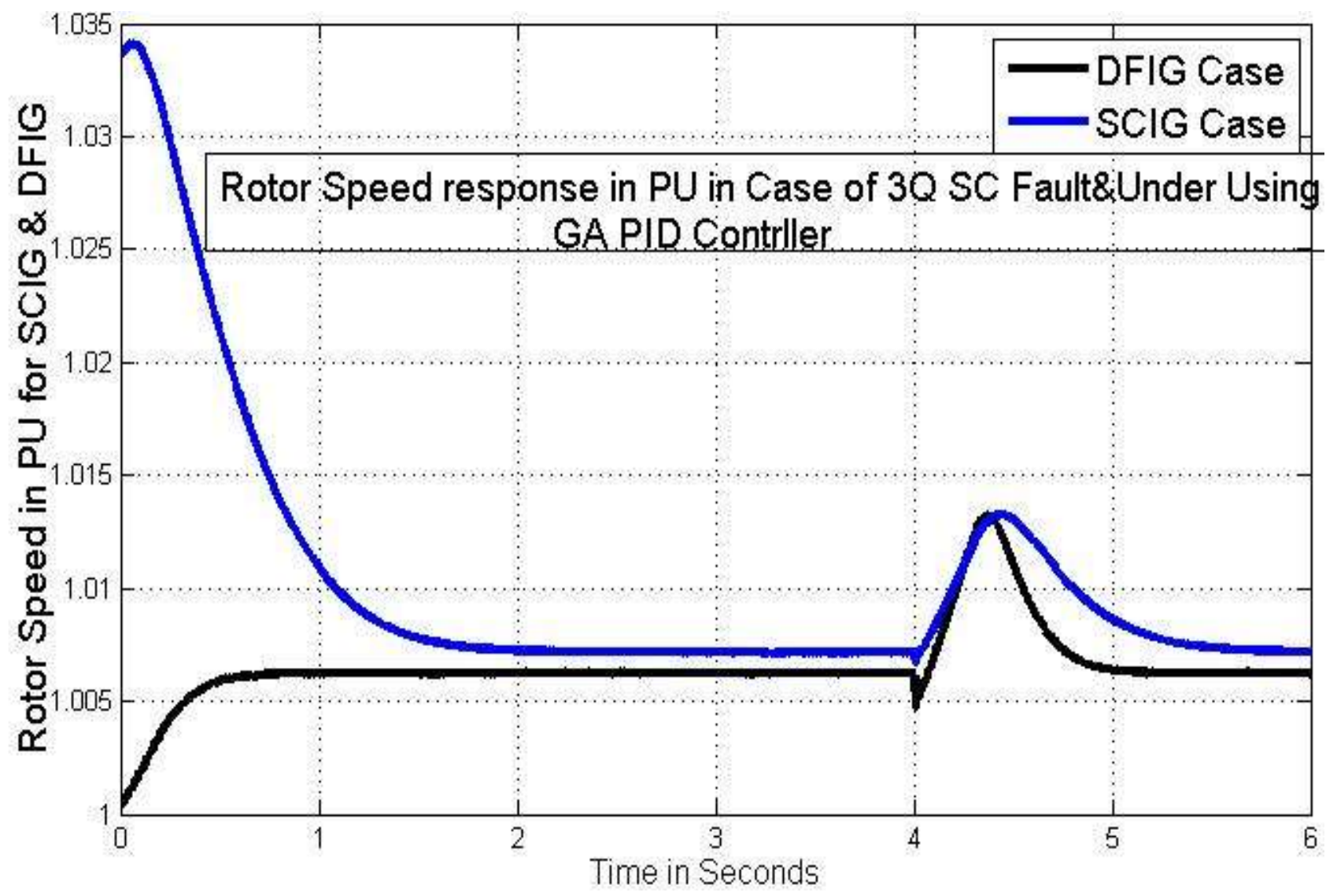

Figure 11: The Rotor Speed of Both Generators. 


\section{CONCLUSION}

This research gives an overview about the different types of generators used in the wind systems like DFIG and SCIG, showing the difference between them and the performance of each during abnormalities like three-phase short-circuit fault in the presence of PID controller tuned by GA technique. Also, a short description is provided showing the genetic algorithm technique and the main operation steps of it to get the optimal values of the PID controller gains. Finally, from the results and the different analysis in this work, it's highly recommended to use the DFIG in most of the wind systems applications, this is due to its smooth performance and its ability to cope up with the system changes and disturbances.

\section{REFERENCES}

[1] Pawlas, G.E., 2018. Wind Energy. In Principles of Sustainable Energy Systems, Third Edition (pp. 269-330). CRC Press.

[2] Ben Smida, M. and Sakly, A., 2016. Pitch angle control for grid-connected variable-speed wind turbine system using fuzzy logic: A comparative study. Wind Engineering, 40(6), pp.528-539.

[3] Eckstein, R.H., Lazzarin, T.B. and Barbi, I., 2014. Proposed power and control system for small scale wind turbines connected to the grid.

[4] Ahuja, H., Sharma, S., Singh, G., Sharma, A. and Singh, A., 2016, February. Coordinated Fault Ride through Strategy for SCIG Based WECS. In Computational Intelligence \& Communication Technology (CICT), 2016 Second International Conference on (pp. 424-429). IEEE.

[5] Mahony, T.O., Downing, C.J. and Fatla, K., 2000. Genetic algorithm for PID parameter optimization: minimizing error criteria. Process control and instrumentation, pp.26-28.

[6] Zoghby, H.M.E. and Sharaf, S.M., 2011. Dynamic Response of a Grid Connected Wind Farm with Different Types of Generators. International Journal of Power Electronics and Drive Systems (IJPEDS), 2(1), pp.85-98.

[7] Riachy, L., Azzouz, Y. and Dakyo, B., 2016, October. Optimal power coefficient for load balancing and reactive power compensation in DFIG-WTS. In IECON 2016-42nd Annual Conference of the IEEE Industrial Electronics Society (pp. 4199-4204). IEEE.

[8] Harby, M.E.M., Elmasry, S.E. and El Samahy, A., 2017, December. Fault analysis and control of a grid connected wind turbine driving squirrel cage induction generator using genetic algorithm PID controller. In 2017 Nineteenth International Middle East Power Systems Conference (MEPCON) (pp. 1328-1332). IEEE.

[9] Faúndez, P., 2017. Renewable energy in the equilibrium mix of electricity supply sources. Energy Economics, 67, pp.28-34.

[10] Díaz-González, F., Hau, M., Sumper, A. and Gomis-Bellmunt, O., 2014. Participation of wind power plants in system frequency control: Review of grid code requirements and control methods. Renewable and Sustainable Energy Reviews, 34, pp.551-564.

[11] Dragomir, D., Golovanov , N., Postolache, P. and Toader, C., 2009, June. The connection to the grid of wind turbines. In PowerTech, 2009 IEEE Bucharest (pp. 1-8). IEEE.

[12] Konstantopoulos, G.C. and Alexandridis, A.T., 2014. Full-scale modeling, control, and analysis of grid-connected Wind turbine induction generators with back-to-back AC/DC/AC converters. IEEE journal of emerging and selected topics in power electronics, 2(4), pp.739-748.

[13] Ghosh, S., Kamalasadan, S., Senroy, N. and Enslin, J., 2016. Doubly fed induction generator (DFIG)-based wind farm control framework for primary frequency and inertial response application. IEEE Transactions on Power Systems, 31(3), pp.1861-1871.

[14] Wright, A.D., 2009. Wind turbine control systems. In Wind Turbine Technology: Fundamental Concepts in Wind Turbine Engineering, Second Edition. ASME Press.

[15] Slootweg, J.G., Polinder, H. and Kling, W.L., 2001, July. Dynamic modelling of a wind turbine with doubly fed Induction generator. In 2001 Power Engineering Society Summer Meeting. Conference Proceedings (Cat. No. 01CH37262) (Vol. 1, pp. 644-649). IEEE.

[16] Bianchi, F.D., Mantz, R.J. and De Battista, H., 2007. The wind and wind turbines (pp. 7-28). Springer London.

[17] Ekanayake, J. and Jenkins, N., 2004. Comparison of the response of doubly fed and fixed-speed induction generator wind turbines to changes in network frequency. IEEE Transactions on Energy conversion, 19(4), pp.800-802.

[18] Muller, S., Deicke, M. and De Doncker, R.W., 2002. Doubly fed induction generator systems for wind turbines. IEEE Industry applications magazine, 8(3), pp.26-33. 